九州大学学術情報リポジトリ

Kyushu University Institutional Repository

\title{
Removal of Chlorophenols by Fungal Laccase in the Presence of Aromatic Alcohols
}

Cho, Nam-Seok

Wood and Paper Science, Chungbuk National University

Jarosz-Wilkolazka, Anna

Marie Curie-Sklodowska University

Cho, Hee-Yeon

Dental Research Institute, School of Dentistry, UCLA

Leonowicz, Andrzej

Marie Curie-Sklodowska University

他

https://doi.org/10.5109/9275

出版情報：九州大学大学院農学研究院紀要. 52 (1)，pp.23-27，2007-02-28. Faculty of Agriculture， Kyushu University

バージョン :

権利関係 : 


\title{
Removal of Chlorophenols by Fungal Laccase in the Presence of Aromatic Alcohols

\author{
Nam-Seok CHO ${ }^{1}$, Anna JAROSZ-WILKOLAZKA ${ }^{2}$, Hee-Yeon CHO $^{3}$, \\ Andrzej LEONOWIC ${ }^{2}$ and Shoji OHGA* ${ }^{4 *}$
}

\author{
Laboratory of Forest Resources Management, Division of Forest Ecosphere Management, \\ Department of Forest and Forest Products Sciences, Kyushu University, \\ Sasaguri, Fukuoka 811-2415, Japan \\ (Received November 9, 2006 and accepted December 1, 2006)
}

\begin{abstract}
The effect of aromatic alcohols, coniferyl, sinapyl, vanillyl and iso-vanillyl alcohols, on the removal of chlorinated phenols from water environment by fungal laccases from Cerrena unicolor and Rhizoctonia praticola was studied. In optimal conditions all tested alcohols removed about 30 to $60 \%$ of chlorophenols from the supernatant, compared to that of laccase alone. $R$. praticola at $\mathrm{pH} 7.0$ significantly removed more chlorophenols from supernatant than in the case of $C$. unicolor at $\mathrm{pH}$ 5.5. The laccase reaction is independent on the enzyme source and favours higher $\mathrm{pH}$ condition. Tested chlorophenols were partly coupled with aromatic alcohols and sedimented. It almost linearly depended on amounts of chlorine atoms in chlorophenols; more chlorine atoms resulted in higher yield of coupling reaction.
\end{abstract}

\section{INTRODUCTION}

Chlorophenols produced by industry on a large scale are widespread pollutants accumulating in soil and water environments (Cho et al., 2001). As conventional (chemical) methods of wastewater treatment such as activated sludge or aerated lagoons are rather ineffective (Bergbauer et al., 1991), recently biological method received more attention. Among organisms showing biodegradation potency, wood rotting terrestrial fungi seem to be the most promising. These fungi, which are capable to degrade lignin in wood, show also potency to degrade many structurally diverse organic pollutants (Kang and Stevens, 1994). The removal of xenobiotic compounds from water effluent is presently understood as an enzymatic process with probably predominant function of fungal laccase (benzenediol:oxygen oxidoreductase, EC 1.10.3.2) (Ruggiero et al., 1989; Roy-Arcand and Archibald, 1991; Dec and Bollag, 1994; Roper et al., 1995; Cho et al., 1999 and Cho et al., 2001).

Dechlorination can be achieved with laccase (Lyr, 1963; Konishi and Inoue, 1972; Ruggiero et al., 1989; Roy-Arcand and Archibald, 1991; Cho et al., 2001) in the presence of some lignin residues from coupling process (Roy-Arcand and Archibald, 1991). This oxidative coupling process can function in two steps: firstly chlorophenols with aromatic co-substrates (hydrogen donors) are enzymatically oxidised to free radicals or reactive quinines, and then subsequent

\footnotetext{
1 Wood and Paper Science, Chungbuk National University, Cheongju 361-763, Korea

2 Department of Biochemistry, Marie Curie-Sklodowska University, Lublin 20-031, Poland

3 Dental Research Institute, School of Dentistry, UCLA, LA, California 90095, USA

${ }^{4}$ Dept. of Forest and Forest Products Science, Kyushu University, Sasaguri, Fukuoka 811-2415, Japan

* Corresponding author (E-mail: ohgasfor@mbox.nc.kyushu-u. ac.jp)
}

oxidative coupling of the products is completed without further involvement of the enzyme (Dec and Bollag, 1994; Dec and Bollag, 1995). Chlorophenolic removal from water environment can be accomplished by coupling reaction of chlorophenols with some low molecular aromatic laccase substrates, e.g. guaiacol and 2,6-dimethoxyphenol (Dec and Bollag, 1994 and 1995; Roper et al., 1995). However, since guaiacol or 2,6-dimethoxyphenol remaining in supernatants are still not indifferent, we proposed coniferyl alcohol to investigate in the coupling process more acceptable for the environment (Cho et al., 1999). Coniferyl alcohol is known as a polymerizing compound during lignin biosynthesis in vivo, and as the substrate for in vitro enzymatic production of lignin modeling dehydrogenative polymer - DHP (Sterjiades et al., 1996).

The objective of this study was to investigate the effect of fungal laccase with aromatic alcohols, sinapyl alcohol, vanillyl alcohol and iso-vanillyl alcohol, as the co-polymerizing factors on the removal of chlorophenols.

\section{MATERIALS AND METHODS}

\section{Fungi}

Cerrena unicolor (Bull. ex Fr.) Murr. No. 139 and Rhizoctonia praticola (De Candelle ex Fr.) No. 93 were from the Fungal Culture Collection (FCL) of the Department of Wood and Paper Science, Chungbuk National University, Cheongju, Korea and Department of Biochemistry, University of Lublin, Poland. The fungi were maintained on $2 \%$ (wt/vol) malt agar slants.

\section{Culture condition}

For inoculation the fungal agar plugs (ca. $0.5 \mathrm{~cm}$ ) were cut and grown in a basal medium based on the Czapek Dox and Lindeberg media (Leonowicz et al., 1984). The medium $\mathrm{pH}$ was adjusted to $\mathrm{pH} 5.5$ and 7.0 optimal for $C$. unicolor and $R$. praticola cultures, respectively, and sterilized at $0.075 \mathrm{MPa}$ for $30 \mathrm{~min}$. The 
culture solution was grown static in conical flasks at $27^{\circ} \mathrm{C}$ till the mycelium occupied the whole surface of the liquid. The mycelial mats were collected, homogenized in a Warring Blender and used as inoculums for further incubation. The basal medium $\mathrm{pH}$ was adjusted to the initial pH 5.5 and 7.0, respectively, and sterilized same as described above. The shallow stationary cultures, after inoculation with $4 \%(\mathrm{vol} / \mathrm{vol})$ of the mycelium homogenate, were incubated in $1000 \mathrm{ml}$ flat (Roux type) flasks with $150 \mathrm{ml}$ medium at $27^{\circ} \mathrm{C}$. The cultures were grown up to the period corresponding to the maximum of enzyme activity in the culture fluids.

\section{Determination of laccase activity}

Laccase activity was measured at $20^{\circ} \mathrm{C}$ and at pH 5.5 and 7.0 on a Shimadzu UV 160 A spectrophotometer with 4-hydroxy-3,5-dimethoxy benzaldehyde azine as a substrate, but MES-NaOH buffer utilized by Leonowicz and Grzywnowicz (1981) was replaced by $0.1 \mathrm{M}$ citrate-phosphate buffer (Bollag and Leonowicz, 1984). To exclude endogenous peroxide, a $10 \mathrm{~min}$. preincubation (stirring) of the enzyme sample with catalase $\left(10 \mathrm{mg} \mathrm{ml}^{-1}\right.$ ) was performed. The activity was expressed in international units, (i.e., in nkats $\mathrm{l}^{-1}$, by assuming a molar absorption coefficient of 65,000 (Leonowicz and Grzywnowicz, 1981) at $525 \mathrm{~nm}$ for the coloured (red) reaction product.

\section{Purification of laccase}

For the purification of constitutive $T$. versicolor laccase, we used the method described earlier by Bollag and Leonowicz (1984), and for constitutive C. unicolor laccase the same method but modified further by Kim et al. (2002). The fractions of both laccases around the top of the activity (one peak each) eluted by $\mathrm{NaCl}$ were collected, dialysed to $0.1 \mathrm{M}$ phosphate buffer, $\mathrm{pH} 5.5$ and 7.0 respectively and used for further experiments.

\section{Enzymatic treatment}

For the reaction of aromatic alcohols with particular chlorophenols we directly applied the method described by Kirk and Brunow (1988), but laccase, instead of horseradish peroxidase, was applied with some other modifications as follows. All experiments were done at laboratory temperature (about $22^{\circ} \mathrm{C}$ ). Aromatic alcohols, sinapyl alcohol, vanillyl alcohol and iso-vanillyl alcohol, were dissolved in $2 \mathrm{ml}$ acetone and added (with stirring, under nitrogen) to $40 \mathrm{ml}$ of degassed $0.01 \mathrm{M}$ sodium phosphate buffer at $\mathrm{pH}$ 6.5. The clear mixture was permanently flushed with nitrogen up to the enzyme addition. The second vessel containing 10,000 nkat laccase from either $R$. praticola or C. unicolor in $40 \mathrm{ml}$ of the same sodium phosphate buffer was $20 \mathrm{~min}$ stirred without flushing and $10 \mathrm{~min}$ preincubated (stirring) with catalase $\left(10 \mathrm{mg} \mathrm{ml}^{-1}\right)$ to exclude endogenous peroxide. In the separate vessel $0.5 \mathrm{mM}$ of chlorophenol was dissolved in $20 \mathrm{ml}$ of the same buffer including $50,000 \mathrm{dpm} \mathrm{ml}^{-1}$ of the respective ${ }^{14} \mathrm{C}-$ chlorophenol. Then, to vessel containing chlorophenols, aromatic alcohols and the enzyme solutions were either slowly added (dropping both without flushing over $20 \mathrm{hr}$ with continuous stirring in darkness) or at once simultaneously added and stirred. Samples with boiled laccase were controls for determining adsorption of chlorophenols to eventually precipitated enzyme. Laccase activity was stopped by the addition of $65 \mu \mathrm{l} \mathrm{ml}^{-1}$ of 10\% sodium azide (Bollag and Leonowicz, 1984). Each sediment was recovered by centrifugation (15,000 g for $30 \mathrm{~min}$ ), washed with water (twice), evaporated in a rotary evaporator and analysed by phloroglucinol method indicating the presence of a "lignin-like" products (Trojanowski and Leonowicz, 1962). The radioactivities of the supernatants and controls were measured with Scintillation Counter as described Leonowicz et al. (1972).

\section{Determination of protein}

The protein content was determined according to Lowry et al. (1951) by using bovine serum albumin as a standard (Bollag and Leonowicz, 1984). The quantity of protein bound on sediment was calculated by subtracting the protein in the combined original liquid before laccase reaction and the supernatant and wash after incubation with the enzyme.

\section{Chemicals}

Sinapyl, vanillyl and iso-vanillyl alcohols, phloroglucinol, 4-chlorophenol, 2,4-dichlorophenol, 2,4,5-trichlorophenol, pentachlorophenol and syringaldazine were purchased from Aldrich-Chemie (Steinheim, Germany), and then ${ }^{14} \mathrm{C}$-ring-labelled chlorophenols were from Pathfinder Laboratories (St Louis, Mo). Sephadex G-25 was from Pharmacia (Uppsala, Sweden) and DEAE-Cellulose 23-SS from Serva (Heidelberg, F.R.G.)

\section{RESULTS AND DISCUSSION}

According to Kirk and Brunow (1988) pH higher than 5.5 is a more convenient for polymerization of coniferyl alcohol (optimum at pH 6.5). Fig. 1 shows $\mathrm{pH}$ optima for $C$. unicolor and $R$. praticola laccases appearing at pH 5.5 and 7.0, respectively. Both optima seem to be more close to essential for our experiments value, than ones of laccases from other fungi existing usually between pH 3.5 and 4.5. Each laccase of those fungi usually does not show any activity at pH 7.0. As can be seen in Fig. 1, at pH 7.0 remains a meaning amount of $C$. unicolor laccase activity, at least 40\% (at pH 5.5 remains around $50 \%$ of $R$. praticola laccase). These amounts are sufficient for our studies. Similar experiments with adjustment of $\mathrm{pH}$ were also demonstrated elsewhere (Leonowicz et al., 1984)

To avoid confusing for our results adsorption of phenolic inducers to the tested enzymes, we incubated our fungi in the conditions favouring to the production of a constitutive laccase. For this reason sugar-rich medium was helpful. The enzyme is known to occur in fungi as constitutive and inducible forms (Leonowicz and Trojanowski, 1975; Leonowicz and Trojanowski, 


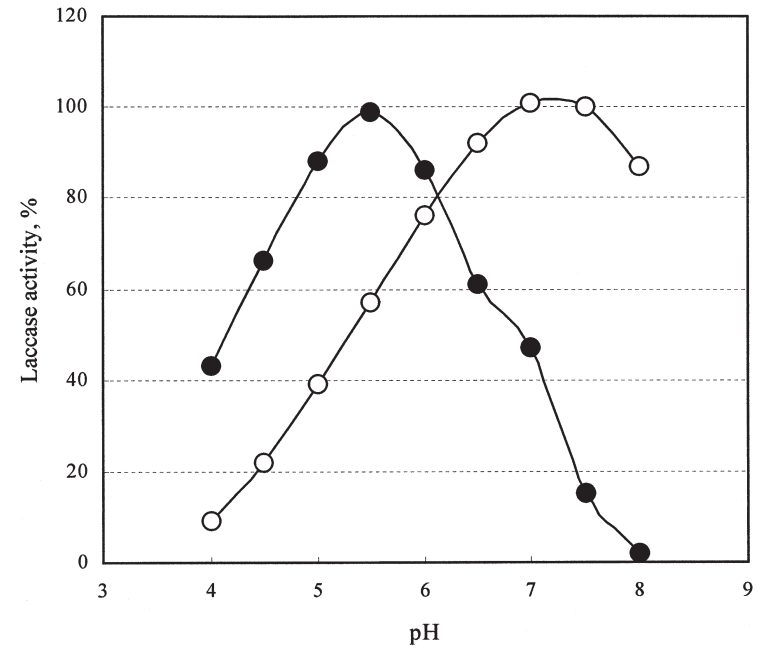

Fig. 1. The effect of $\mathrm{pH}$ on the activity of $C$. unicolor and $R$. praticola laccases. C. unicolor; $\bigcirc$ R. praticola

1975a; Worall et al., 1986; Wahleithner et al., 1996). An excess amount of glucose in liquid medium allowed for the production of constitutive laccase by the fungi, whereas the biosynthesis of the inducible enzyme forms were repressed by glucose addition (Bollag and Leonowicz, 1984, Manzanares et al., 1995). In this experiment four chlorophenols were separately incubated with particular aromatic alcohol and both laccases. No significant removal of chlorophenols was observed in the controls. The results are presented in Fig. 2-Fig. 6.

Under the conditions employed, all the tested chlorophenols were partly removed from the initial solution. For example in $2 \mathrm{mM}$ coniferyl alcohol (Fig. 2), the incubation with laccase of $C$. unicolor at $\mathrm{pH} 5.5$ has removed 4-chlorophenol by $22 \%, 2,4$-dichlorophenol by 48\%, 2,4,5-trichlorophenol by $52 \%$ and pentachlorophenol by even $71 \%$, compared to the level without laccase activity. The results for $R$. praticola were 34\%, 57\%,

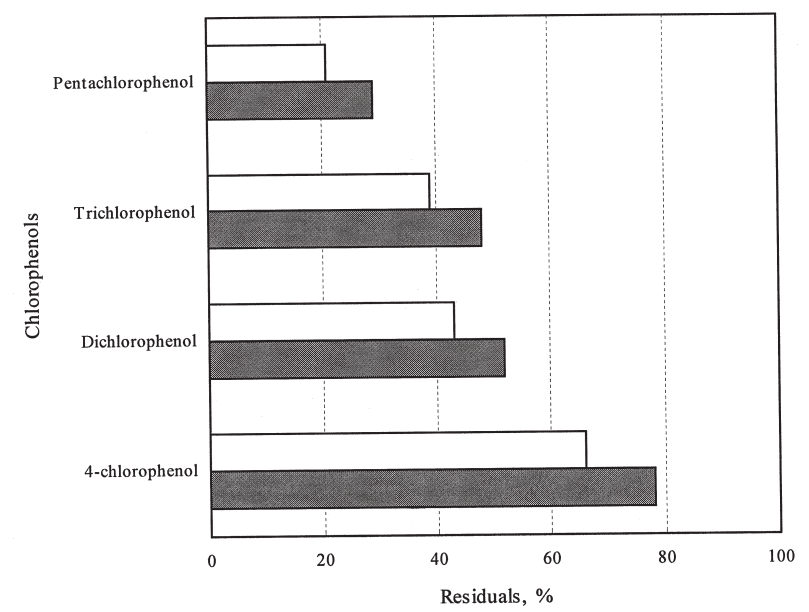

Fig. 2. Effect of coniferyl alcohol on the removal of ${ }^{14} \mathrm{C}-$ chlorophenols from the supernatants by $C$. unicolor and $R$. praticola laccases. $\square$ C. unicolor; $\square$ R. praticola
$61 \%$ and $79 \%$, respectively, for particular chlorophenols. In the case of sinapyl alcohol (see Fig. 3), 4-chlorophenol by $22 \%$, 2,4-dichlorophenol by $41 \%$, 2,4,5-trichlorophenol by $45 \%$ and pentachlorophenol by $59 \%$ were removxed for $C$. unicolor. The results for $R$. praticola were 34\%, 45\%, 63\% and 77\% removals, respectively, for particular chlorophenols (see Fig. 3). The similar results were obtained now with vanillyl alcohol (Fig. 4), and iso-vanillyl alcohol (Fig. 5). In chlorophenols, pentachlorophenol was removed very easily. In all experiments the best result was given by coniferyl alcohol, followed by sinapyl, vanillyl and isovanillyl alcohols (see Fig. 6).

In all experiments using either laccase form $C$. unicolor or $R$. praticola, it would be believed that tested chlorophenols were partly coupled with aromatic alcohols and sedimented during centrifugation. It almost linearly depended on amount of chlorine atoms in chlorophenols; more chlorine atoms resulted in higher

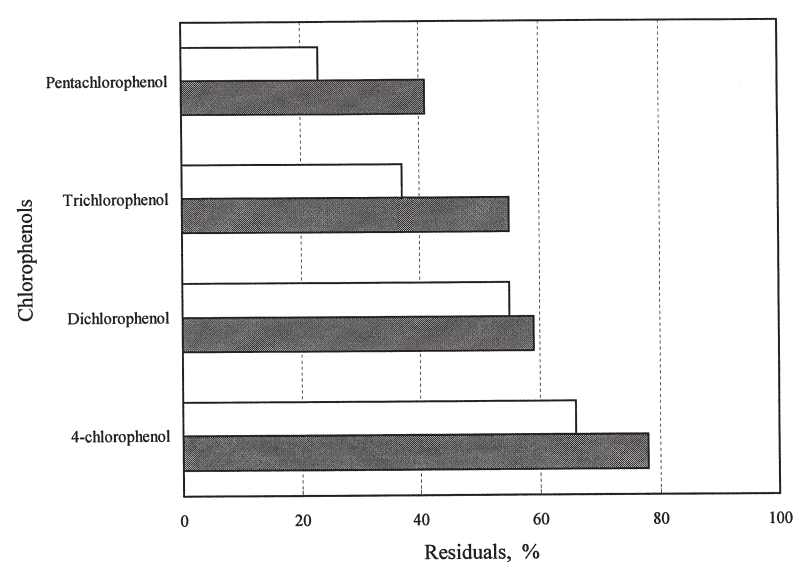

Fig. 3. Effect of sinapyl alcohol on the removal of ${ }^{14} \mathrm{C}-$ chlorophenols from the supernatants by $C$. unicolor and $R$. praticola laccases. $\square$ C. unicolor; $\square$ R. praticola

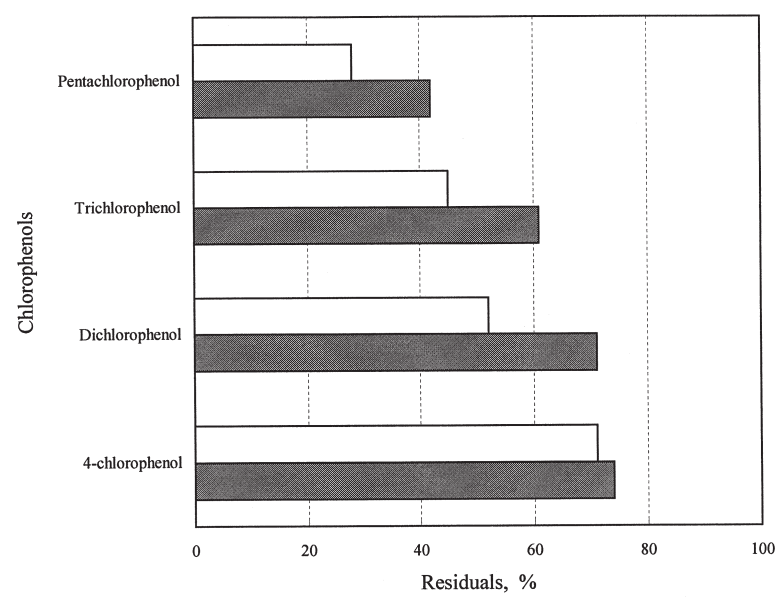

Fig. 4. Effect of vanillyl alcohol on the removal of ${ }^{14} \mathrm{C}$-chlorophenols from the supernatants by $C$. unicolor and $R$. praticola laccases. $\square$ C. unicolor; $\square$ R. praticola 


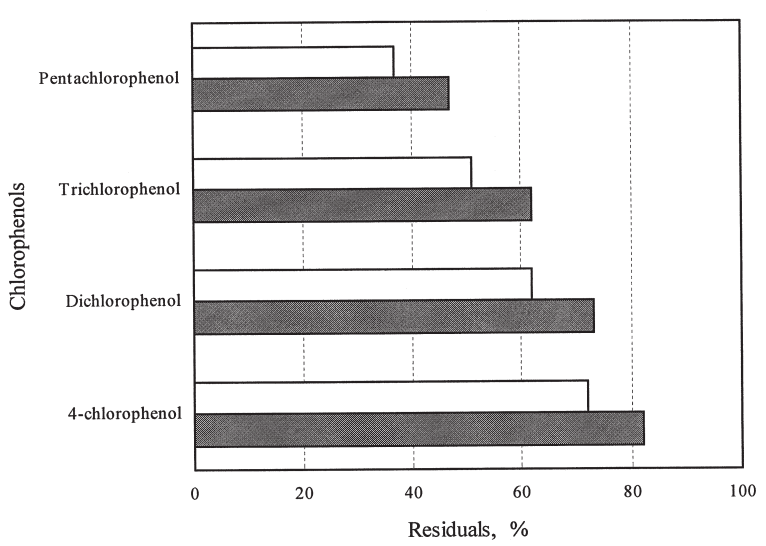

Fig. 5. Effect of iso-vanillyl alcohol on the removal of ${ }^{14} \mathrm{C}$-chlorophenols from the supernatants by C. unicolor and $R$. praticola laccases. $\square$. unicolor; $\square$ R. praticola

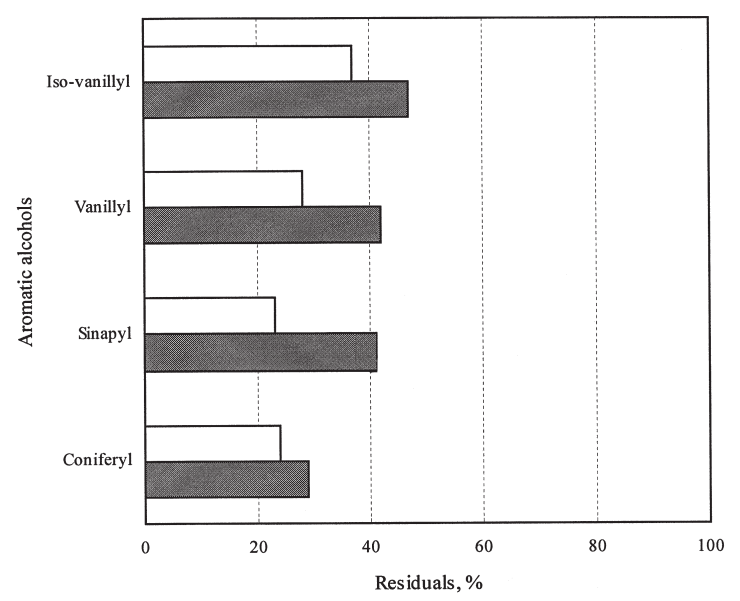

Fig. 6. Effect of $C$. unicolor and $R$. praticola laccases and aromatic alcohols on the removal of ${ }^{14} \mathrm{C}-$ chlorophenol from the supernatants. $\square$ C. unicolor; $\square$ R. praticola

yield of coupling reaction products. This relationship repeated in the experiments with both fungi (Fig. 2). However, R. praticola at pH 7.0 significantly removed more chlorophenols from supernatant than in the case of $C$. unicolor at $\mathrm{pH}$ 5.5. These results were a little lower removal in comparison with results obtained earlier for coniferyl alcohol (Cho et al., 1999), which showed about $40 \%$ of 4-chlorophenol, 54\% of 2,4-dichlorophenol, 60\% of 2,4,5-trichlorophenol and even $76 \%$ of pentachlorophenol, compared to the level without laccase activity.

Any meaningful differences in the results were not noticed, what confirms earlier results, where activity of two different laccases on vanillic and syringic acids was investigated (Leonowicz et al., 1984). In that case it was unequivocally stated that the laccase reaction is independent on the enzyme source and favours higher pH conditions (Leonowicz et al., 1984). For confirmation of this fact, we followed the experiments with applying $\mathrm{pH} 7.0$ for laccase of $C$. unicolor and 5.5 for the enzyme isolated from $R$. praticola. The results were almost similar as earlier. When we tested laccases of $C$. unicolor at $\mathrm{pH} 5.5$ and $R$. praticola at $\mathrm{pH} 7.0$, it confirms independency of reaction from source of the enzyme and dependency from $\mathrm{pH}$.

The laccase enzyme is known from its ability to production of quinoid oligomers from some toxic chlorophenols (Minard et al., 1981). The enzyme is also able to directly dechlorinate a number of chlorinated phenols. The oldest report regarded partial dechlorination of pentachlorophenol by Trametes versicolor laccase (Lyr, 1963). Furthermore Konishi and Inoue (1972) reported that pentachlorophenol is primarily converted by Coriolus versicolor laccase to chloranil or tetrachloro-benzchinone, and then products combine with PCP yielding benzoquinone dimers or trimers. Finally Roy-Arcand and Archibald (1991) indicated a rapid partial dechlorination of many chlorinated and polychlorinated phenols by three laccases from Trametes versicolor. Presented our earlier report (Cho et al., 1999) and this report confirming the coupling reaction point to one more method for removal of toxic chlorophenols from water environment. In both experiments either $C$. unicolor or $R$. praticola laccase could be applied. Our present experiments confirmed also the thesis that coupling reactions prefer higher $\mathrm{pH}$. These aromatic alcohol compounds, especially iso-vanillyl alcohol, are much cheaper than coniferyl alcohol. Additively, using vanillyl or iso-vanillyl alcohol allows for saving money. In our coupling experiments we obtained the sediment, which was dissolved in the mixture of ethyl alcohol and ethylene chloride, and gave a red colour with phloroglucinol-HCl. This positive result of phloroglucinol test shows the coupling reaction of some aldehyde group of the sediment with phloroglucinol (Trojanowski and Leonowicz, 1962). Such polymeric, insoluble sediments produced during coupling reaction may be used for enriching of soil humus.

\section{CONCLUSIONS}

This study was carried out to investigate the effect of fungal laccase with aromatic alcohols, sinapyl alcohol, vanillyl alcohol and iso-vanillyl alcohol, as the co-polymerizing factors, on the removal of chlorophenols. In optimal conditions all tested alcohols removed about 30 to $60 \%$ of chlorophenols from the supernatant, compared to that of laccase alone. $R$. praticola at $\mathrm{pH} 7.0$ significantly removed more chlorophenols from supernatant than in the case of $C$. unicolor at $\mathrm{pH}$ 5.5. The laccase reaction is independent on the enzyme source and favours higher $\mathrm{pH}$ condition. Tested chlorophenols were partly coupled with aromatic alcohols and sedimented. It almost linearly depended on amounts of chlorine atoms in chlorophenols; more chlorine atoms resulted in higher yield of coupling reaction.

\section{ACKNOWLEDGEMENTS}

Some parts of this research were carried out with 
the support of the 6-PR of the European Community, proposal No 505899-2 (acronym SOPHIE D), the Committee for Scientific Investigations BS/BiNoZ/4 and I/WBiNoZ/Inst., and Brain Pool Program of KOFST and KOSEF (2003-032S-4-6).

\section{REFERENCES}

Bergbauer, M., C. Eggert and G. Kraepelin 1991 Degradation of chlorinated lignin compounds in a bleach plant effluent by the white-rot fungus Trametes versicolor. Appl. Microbiol. Biochem., 35: 105-109

Bollag, J. M. and A. Leonowicz 1984 Comparative studies of extracellular fungal laccases. Appl. Environ. Microbiol., 48: $849-854$

Cho, N. S., J. H. Nam, J. M. Park, C. D. Koo, S. S. Lee, N. Pashenova, S. Ohga and A. Leonowicz 2001 Transformation of chlorophenols by white-rot fungi and their laccase. Holzforschung, 55: 579-584

Cho, N. S., J. Rogalski, M. Jaszek, J. Luterek, M. Wojtas-Wasilewska, E. Malarczyk, M. Fink-Boots and A. Leonowicz 1999 Effect of coniferyl alcohol addition on removal of chlorophenols from water effluents by fungal laccase. J. Wood Sci., 45: 174-178

Dec, J. and J. M. Bollag 1994 Dehalogenation of chlorinated phenols during oxidative coupling. Environ. Sci. Technol., 28: $484-490$

Dec, J. and J. M. Bollag 1995 Effect of various factors on dehalogenation of chlorinated phenols and anilines during oxidative coupling. Environ. Sci. Technol., 29: 657-663

Kang, G. and D. K. Stevens 1994 Degradation of pentachlorophenol in bench scale bioreactors using the white rot fungus Phanerochaete chrysosporium. Haz. Waste Haz. Mat., 11: 397-410

Kim, Y., N. S. Cho, T. J. Eom and W. Shin 2002 Purification and characterization of a laccase from Cerrena unicolor and its reactivity in lignin degradation. Bull. Korean Chem., 23: 985-989

Kirk, T. K. and G. Brunow 1988 Synthetic ${ }^{14} \mathrm{C}-$ labeled lignin. Methods Enzymol., 161: 65-73

Konishi, K. and Y. Inoue 1972 Detoxification mechanism of pentachlorophenol by the laccase of Coriolus versicolor. Mokuzai Gakkaishi, 18: 463-469

Leonowicz, A. and K. Grzywnowicz 1981 Quantitative estimation of laccase forms in some white-rot fungi using syringaldazine as a sub-strate. Enzyme Microbiol. Technol., 3: 55-58

Leonowicz, A. and J. Trojanowski 1975 Induction of laccase by ferulic acid in Basidiomycetes. Acta Biochim. Polon., 22: 291-295

Leonowicz, A. and J. Trojanowski 1975a Induction of a new laccase form in the fungus Pleurotus ostreatus by ferulic acid. Microbios., 13: 167-174

Leonowicz, A., R. U. Edgechill and J. M. Bollag 1984 The effect on the transformation of syringic and vanillic acids by the laccases of Rhizoctonia praticola and Trametes versicolor. Arch. Microbiol., 137: 89-96

Leonowicz, A., J. Trojanowski and G. Nowak 1972 Ferulic acid as inductor of messenger RNA synthesis related to laccase formation in wood rotting fungus Pleurotus ostreatus. Microbios, 6: 23-28

Lowry, O. H., N. J. Rosebrough, A. L. Farr and R. J. Randall 1951 Protein measurement with the Folin phenol reagent. J. Biol. Chem., 193: 265-275

Lyr, H. 1963 Enzymatische detoxifikation chlorierter phenole. Phytopathol. Z., 47: 73-82

Manzanares, P., S. Fajardo and C. Martin 1995 Production of ligninolytic activities when treating paper pulp effluents by Trametes versicolor. J. Biotechnol., 43: 15-132

Minard, R. D., S. Y. Liu, and J. M. Bollag 1981 Oligomers and quinones from 2,4-dichlorophenol. J. Agric. Food Chem., 29: 250-253

Ropper, J. C., J. D. Sarkar, J. Dec and J. M. Bollag 1995 Enhanced enzymatic removal of chlorophenols in the presence of co-substrates. Wat. Res., 29: 2720-2724

Roy-Arcand, L. and F. S. Archibald 1991 Direct dechlorination of chlorophenolic compounds by laccases from Trametes versicolor. Enzyme Microbiol. Technol., 13: 194-203

Ruggiero, P., J. M. Sarkar and J. M. Bollag 1989 Detoxification of 2,4-dichlorophenol by a laccase immobilized in soil or clay. Soil Sci., 147: 361-370

Sterjiades, R., P. Ranocha, A. M. Boudet and D. Goffner 1996 Identification of specific laccase isoforms capable of polymerizing monolignols by an "in-gel" procedure. Anal. Biochem., 242: 158-161

Trojanowski, J. and A. Leonowicz 1962 A quantitative determination of Björkman's lignin in a solution by reaction with phloroglucinol. Ann. Univ. M. C.-Sklodowska, Sectio AA., 17: $121-126$

Wahleithner, J. A., F. Xu, K. M. Brown, S. H. Brown, E. J. Golithly, T. Halkier, S. Kauppinen, A. Pederson and P. Shneider 1996 The identification and characterization of four laccases from the plant pathogenic fungus Rhizoctonia solani. Curr. Genet., 29: 395-403

Worrall, J. J., I. Chet and A. Hüttermann 1986 Association of rhizomorph formation with laccase activity in Armillariella spp. J. Gen. Microbiol., 132: 2527-2533 